\title{
Effects of regulating the European Internal Market on the integration of variable renewable energy
}

\section{Hugo Algarvio $^{1,2}$ | Fernando Lopes ${ }^{1}$ | António Couto ${ }^{1}$ | João Santana ${ }^{2}$ | Ana Estanqueiro 1}

${ }^{1}$ LNEG - National Laboratory of Energy and Geology, Lisbon, Portugal

${ }^{2}$ Instituto Superior Tecnico, Universidade de Lisboa, Lisbon, Portugal

\section{Correspondence}

Hugo Algarvio, UER - Renewable Energy and Energy Systems Integration Unit, LNEG, Estr. Paço do Lumiar 22, Lisbon, Portugal.

Email: hugo.algarvio@tecnico.ulisboa.pt

Funding information

FCT (Fundação para a Ciência e

Tecnologia), Grant/Award Number:

$\mathrm{PD} / \mathrm{BD} / 105863 / 2014$

\begin{abstract}
The new proposal for regulating the European Internal Market for Electricity (EIME) can motivate the harmonization of the various National markets. The process of harmonizing the day-ahead markets (DAMs) is at an advanced stage, with an efficiency in the use of interconnectors of $86 \%$. However, the harmonization of both intraday (IDMs) and balancing markets (BMs) is still in its infancy, with an efficiency in the use of interconnectors of 50 and 19\%, respectively. The new proposal brings new targets to DAMs, and European countries should make efforts to comply with them. The same is true for IDMs and BMs, but involving more ambitious targets, requiring higher efforts to be accomplished. Both the analysis of the various National markets (according to their compliance with the new proposal for regulating the EIME) and the advantages of the new proposal for key market participants (particularly, consumers, variable renewable generation, and conventional generation) are presented. The analysis indicates that the proposal contributes to a potential increase of the general welfare of market participants. However, some aspects of the proposal can negatively affect the revenue obtained from the National markets, notably for variable renewable generation and conventional generation.

This article is categorized under:

Wind Power $>$ Systems and Infrastructure

Energy Policy and Planning $>$ Economics and Policy

Energy Systems Analysis > Economics and Policy

Energy and Development $>$ Economics and Policy
\end{abstract}

\section{K E Y W O R D S}

European Internal Market, harmonization of European markets, market participants, new proposal of regulation, variable renewable energy integration

\section{1 | INTRODUCTION}

Electricity markets (EMs) are a complex and continuously evolving reality (Expósito, Conejo, \& Cañizares, 2016; Lopes \& Coelho, 2018). Most markets were designed according to the principles proposed in the standard market design, which was set out when the majority of power plants were dispatchable. Variable renewable energy (VRE), with near-zero variable costs, has increased significantly in the past few years. So, the potential impacts of VRE on EMs need to be carefully analyzed to 